\title{
Retrospective Study of Risk Factors for Abruptio Placenta and Assessing Maternal and Fetal Outcome
}

\author{
Dr. K.Sravani ${ }^{1}$, Dr. K. Madhavi ${ }^{2 *}$, M.S (OBG), DGO
}

${ }^{1}$ Junior Resident, Department Of Obstetrics and Gynaecology, GGH Kadapa Andhra Pradesh India

${ }^{2}$ Associate Professor, Department of Obstetrics and Gynaecology, GGH Kadapa Andhra Pradesh India

\author{
DOI: $10.36348 /$ sijog.2019.v02i11.008 \\ | Received: 13.11.2019 | Accepted: 23.11.2019 | Published: 30.11.2019 \\ *Corresponding author: K. Madhavi M.S
}

\section{Abstract}

\begin{abstract}
Aims: Abruptio placenta which is a major cause of maternal morbidity and perinatal mortality globally is of serious concern in the developing world. We retrospectively analysed the abruptio placenta cases and evaluated its impact on maternal and fetal outcomes. Materials and methods: This is a retrospective study conducted in department of Obstetrics and Gynaecology at GGH, KADAPA from April 2018 to June 2019. Patients of abruptio placenta with more than 28 weeks of gestation, presenting with antepartum haemorrhage and their maternal and fetal outcome is evaluated. Results: In our study period we encountered 30 abruptio placenta cases. In 30 patients $11(36 \%)$ patients were presented with preeclampsia, $18(60 \%)$ patients were multiparous, and almost all the patients were having anaemia. These were considered as risk factors for abruptio placenta. All the cases were referred from nearby PHC to our tertiary care hospital, GGH, KADAPA. In our study 3(10\%) patients developed complications, in that 2(6.6\%) patients developed Disseminated Intravascular Coagulation (DIC) and 1(3.33\%) patient had acute kidney injury and no maternal deaths encountered in our study. Regarding fetal outcome 22(73.33\%) patients presented with IUFD by the time of presentation to the hospital and 1(3.33\%) stillbirth, 2(6.6\%) babies admitted in SNCU and 5(16.66\%) were having good Apgar. Conclusion: We observed that higher incidence of anaemia, multiparity and preeclampsia as risk factors in our study population. We need to motivate public regarding the importance of antenatal care, improvement in nutritional status and create awareness about family planning practices. We noticed that early identification and intervention can prevent maternal and perinatal mortality.

Keywords: Abruptio placenta, Anaemia, Preeclampsia, Maternal mortality.

Copyright @ 2019: This is an open-access article distributed under the terms of the Creative Commons Attribution license which permits unrestricted use, distribution, and reproduction in any medium for non-commercial use (NonCommercial, or CC-BY-NC) provided the original author and source are credited.
\end{abstract}

\section{INTRODUCTION}

Abruptio placenta is defined as premature partial or complete separation of normally implanted placenta from the uterine wall [1]. Abruptio placenta is a major cause of maternal mortality and perinatal mortality especially in the developing world [1-4]. Etiology of abruptio placenta is multifactorial, that is, impaired placentation, placental insufficiency, hypertensive disorders of pregnancy, and advanced maternal age, grand multiparity [5]. The signs and symptoms of abruptio placenta vary depending on the severity of bleeding and degree of separation of the placenta $[1-3,6]$. The most common presentations include vaginal bleeding, uterine and abdominal pain and tenderness, abnormal uterine contractions, preterm labour, maternal hemodynamic instability, fetal distress, and fetal death $[1-3,6]$. We conducted this retrospective study to understand the rate of abruptio placenta to identify the associated risk factors and its consequences on maternal and fetal outcome. 


\section{PICTURES}
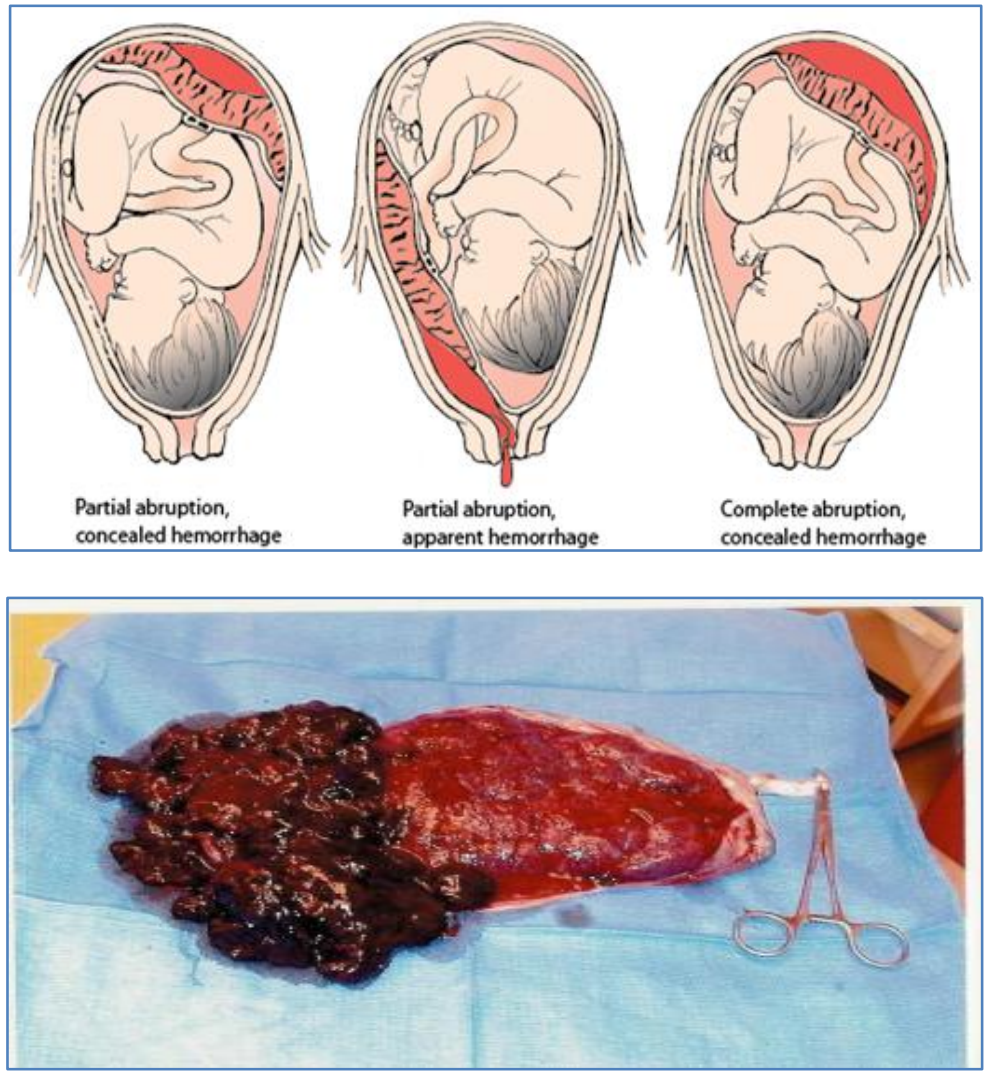

\section{Ultrasonographic picture showing placental abruption}

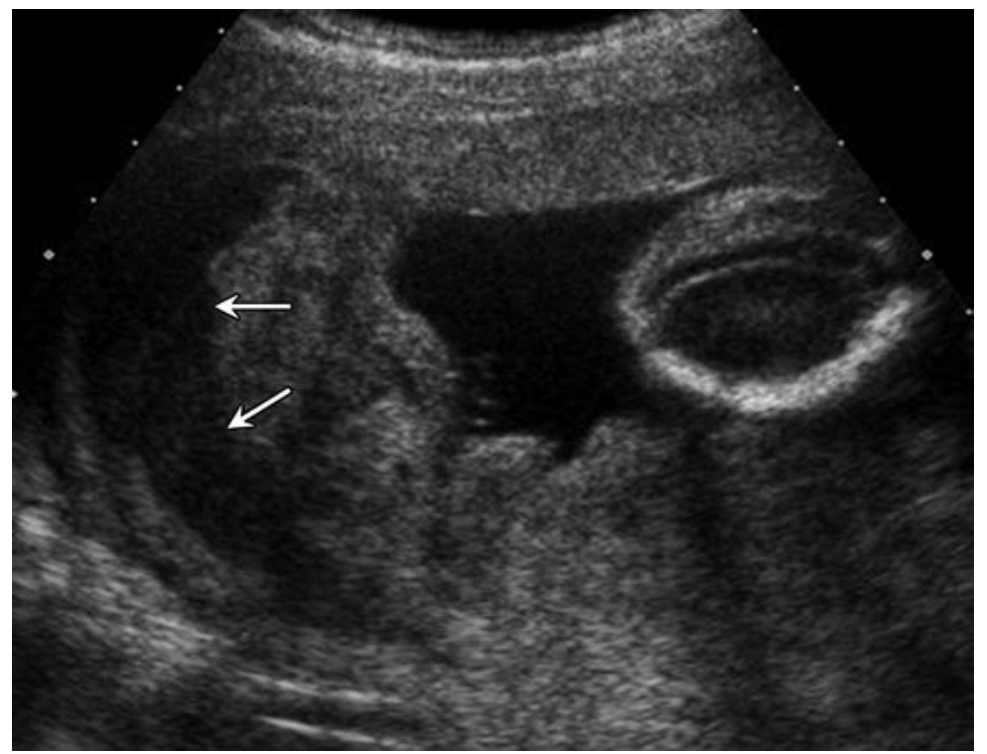

\section{AIMS}

Identification of risk factors of abruptio placenta and evaluation of its impact on maternal and fetal outcome

\section{METHODS}

This retrospective study was carried out in department of Obstetrics and Gynaecology at
Government general hospital Kadapa from April 2018 to June 2019.

\section{Inclusion Criteria}

All women presented with antepartum haemorrhage after 28 weeks of gestation were included. 


\section{Exclusion Criteria}

Obstetric cases with Incidental finding of retroplacental hematoma in the absence of any clinical signs were excluded.

All obstetric cases with abruptio placenta were diagnosed clinically based on clinical symptoms and signs like vaginal bleeding, tense and tender abdomen, hypertonic uterus, and fetal heart variability.

The clinical information regarding maternal age, parity, gestational age at delivery, general condition and hemodynamic status were collected. Medical complications like pre-eclampsia, anaemia were evaluated. Relevant investigations like ultrasonography to confirm the diagnosis.

Blood investigations like haemoglobin, clotting time, bleeding time, platelet count, coagulation profile, renal function tests, liver function tests, cardiotocography to assess fetal well-being were done. Patients were managed according to maternal and fetal condition and complications were documented.

\section{INTERPRETATION OF RESULTS}

Total number of deliveries that were conducted in our hospital were 8048 from April 2018 to June 2019.In that total number of abruptio placenta cases were 30.

Table-I: AGE

\begin{tabular}{|l|l|l|}
\hline AGE & NUMBER OF CASES & PERCENTAGE \\
\hline $18-25$ & 18 & $60 \%$ \\
\hline $26-30$ & 8 & $26.66 \%$ \\
\hline$>30$ & 4 & $13.33 \%$ \\
\hline
\end{tabular}

Table-II: PARITY

\begin{tabular}{|l|l|l|}
\hline PARITY & NUMBER OF CASES & PERCENTAGE \\
\hline G1 & 6 & $20 \%$ \\
\hline G2 & 6 & $20 \%$ \\
\hline G3and above & 18 & $60 \%$ \\
\hline
\end{tabular}

Table-III: ANAEMIA

\begin{tabular}{|l|l|l|}
\hline SEVERITY OF ANAEMIA & NUMBER OF CASES & PERCENTAGE \\
\hline Mild & 3 & $10 \%$ \\
\hline Moderate & 12 & $40 \%$ \\
\hline Severe & 15 & $50 \%$ \\
\hline
\end{tabular}

Table IV: Preeclampsia

\begin{tabular}{|l|l|l|}
\hline & NUMBER OF CASES & PERCENTAGE \\
\hline Preeclampsia & 11 & $36 \%$ \\
\hline
\end{tabular}

Table-V: MODE OF DELIVERY

\begin{tabular}{|l|l|l|}
\hline MODE OF DELIVERY & NUMBER OF CASES & PERCENTAGE \\
\hline Normal vaginal deliveries & 19 & $63 \%$ \\
\hline Emergency caesarean section & 9 & $30 \%$ \\
\hline Hysterotomy & 1 & $3.33 \%$ \\
\hline Preterm delivery & 1 & $3.33 \%$ \\
\hline
\end{tabular}

Table-VI: Blood transfusion and blood products

\begin{tabular}{|l|l|l|}
\hline NUMBER OF UNITS OF BLOOD TRANSFUSION & NUMBER OF CASES & PERCENTAGE \\
\hline 1 Unit & 6 & $20 \%$ \\
\hline 2 Units & 16 & $53 \%$ \\
\hline$>3$ Units & 6 & $20 \%$ \\
\hline Blood products & 13 & $10 \%$ \\
\hline
\end{tabular}

Table-VII: Maternal outcome

\begin{tabular}{|l|l|l|}
\hline COMPLICATIONS & NUMBER OF CASES & PERCENTAGE \\
\hline Disseminated intravascular coagulation & 2 & $6.6 \%$ \\
\hline Acute kidney injury & 1 & $3 \%$ \\
\hline
\end{tabular}


K.Sravani \& Dr. K. Madhavi; Sch Int J Obstet Gynec, Nov. 2019; 2(11): 293-297

Table-VIII: Fetal outcome

\begin{tabular}{|l|l|l|}
\hline FETAL OUTCOME & NUMBER OF CASES & PERCENTAGE \\
\hline Intrauterine fetal demise & 22 & $73.33 \%$ \\
\hline Stillbirth & 1 & $3 \%$ \\
\hline SNCU admission & 2 & $6.6 \%$ \\
\hline Good Apgar & 5 & $16.66 \%$ \\
\hline
\end{tabular}

\section{DISCUSSION}

The incidence rate of Abruptio placenta reported in American, European, and east Asian populations was $0.5 \%-1 \%[1,4,7-9]$.

In our study, almost all patients had anaemia $(\mathrm{Hb}<10 \mathrm{~g} \%)$, however it could not be concluded whether anaemia was the cause or consequence of abruptio placenta. This high frequency of anaemia is reflective of not only bleeding associated with abruptio placenta but is also aggravated by an underlying chronic maternal nutritional deficit commonly prevalent in developing countries ${ }^{5}$.Several preclinical and observational studies have associated micronutrients such as zinc and vitamins with pregnancy complications including placental abruption[9,10].

A low pregnancy weight gain is also associated with abruption placenta [9,11]. The $36 \%$ incidence of preeclampsia observed in our study may be an underestimate owing to masking of hypertensive disorder by lower blood pressures due to vaginal bleeding in patients with abruptio placenta.

Patients with Gestational hypertensive diseases are prone to develop abruption placenta [3]. Hypertension and diabetes mellitus can cause and enhance the placental insufficiency and eventually lead to abruption placenta [2].

In previous study [12] reported 23.6, 10, and $2.3 \%$ incidence of abruption placenta in patients with eclampsia, chronic hypertension, and pre-eclampsia, respectively. Consistent to this grade 3 abruptio placenta was significantly higher among hypertensive patients [12].

In the present study about $13.33 \%$ patients were above 30 years of age. Older maternal age group may be associated with an increase in obstetric complications secondary to a higher incidence of underlying medical disease, decreased cardio vascular reserve and diminished ability to adapt to physical stress thay may accompany ageing [13].

The increased incidence of diabetes and chronic and pregnancy induced hypertension with ageing collaterally increases the incidence of abruption placenta $[13,14]$.

Poor perinatal outcome characterised by high intrauterine deaths observed in our study is consistant with other reports from public sector hospitals in developing countries but in contrast to east Asian, American, and European studies [1, 2, 9].

Rate of caesarean section $(30 \%)$ was high in our study, which was opted in fetal interest as caesarean delivery was associated with significant reduction in neonatal mortality $[2,15]$.

Maternal and fetal outcome can be optimized through attention to risk and benefits of conservative management versus expeditious delivery in cases of abruptio placenta. Hence AP is a major cause of maternal and perinatal morbidity and mortality. The management depends upon extent of abruption, gestational age, and maternal and fetal conditions [5].

\section{CONCLUSION}

To conclude, abruptio placenta is a potentially serious obstetric problem that tends to compromise fetal viability, maternal health and well-being.

Increased frequency of abruptio placenta is observed in women with low socio economic status, and poor nutritional status.

Mass information regarding the importance of antenatal care and improvement in nutritional status may reduce the frequency of abruptio placenta, and thus maternal and fetal morbidity and mortality. Services of the healthcare providers can be taken to identify women at risk, early identification and timely referral of these women for optimal medical management.

\section{SUMMARY}

Early Identification Of Risk Factors And Timely Intervention Can Save Mother And Fetus.

\section{REFERENCES}

1. Pariente, G., Wiznitzer, A., Sergienko, R., Mazor, M., Holcberg, G., \& Sheiner, E. (2011). Placental abruption: critical analysis of risk factors and perinatal outcomes. The Journal of MaternalFetal \& Neonatal Medicine, 24(5), 698-702. Bibi, S., Ghaffar, S., Pir, M. A., \& Yousfani, S. (2009). Risk factors and clinical outcome of placental abruption: a retrospective analysis. Shock, 22, 20.

2. Ananth, C. V., Savitz, D. A., \& Williams, M. A. (1996). Pracental abruption and its association with hypertension and prolonged rupture of membranes: a methodologic review and meta- 
analysis. Obstetrics \& Gynecology, 88(2), 309318.

3. Ananth, C. V., Oyelese, Y., Yeo, L., Pradhan, A., \& Vintzileos, A. M. (2005). Placental abruption in the United States, 1979 through 2001: temporal trends and potential determinants. American journal of obstetrics and gynecology, 192(1), 191198.

4. Mukherjee, S., Bawa, A. K., Sharma, S., Nandanwar, Y. S., \& Gadam, M. (2014). Retrospective study of risk factors and maternal and fetal outcome in patients with abruptio placentae. Journal of natural science, biology, and medicine, 5(2), 425.

5. Tikkanen, M. (2010). Etiology, clinical manifestations, and prediction of placental abruption. Acta obstetricia et gynecologica Scandinavica, 89(6), 732-740.

6. Rasmussen, S., Irgens, L. M., Bergsjø, P., \& Dalaker, K. (1996). The occurrence of placental abruption in Norway 1967-1991. Acta obstetricia et gynecologica Scandinavica, 75(3), 222-228.

7. Kramer, M. S., Usher, R. H., Pollack, R., Boyd, M., \& Usher, S. (1997). Etiologic determinants of abruptio placentae. Obstetrics $\&$ Gynecology, 89(2), 221-226.

8. Hung, T. H., Hsieh, C. C., Hsu, J. J., Lo, L. M., Chiu, T. H., \& Hsieh, T. S. T. A. (2007). Risk factors for placental abruption in an Asian population. Reproductive Sciences, 14(1), 59-65.

9. Christian, P. (2003). Micronutrients and reproductive health issues: an international perspective. The Journal of nutrition, 133(6), 1969S-1973S.

10. Sanchez, S. E., Pacora, P. N., Farfan, J. H., Fernandez, A., Qiu, C., Ananth, C. V., \& Williams, M. A. (2006). Risk factors of abruptio placentae among Peruvian women. American journal of obstetrics and gynecology, 194(1), 225230.

11. Sharief, M., \& Manther, A. A. (1998). Abruptio placentae: Perinatal out come in normotensive and hypertensive patients in Basra, Iraq.

12. Luke, B., \& Brown, M. B. (2007). Elevated risks of pregnancy complications and adverse outcomes with increasing maternal age. Human reproduction, 22(5), 1264-1272.

13. Jahromi, B. N., \& Husseini, Z. (2008). Pregnancy outcome at maternal age 40 and older. Taiwanese journal of obstetrics and gynecology, 47(3), 318321.

14. Witlin, A. G., \& Sibai, B. M. (2001). Perinatal and maternal outcome following abruptio placentae. Hypertension in pregnancy, 20(2), $195-$ 203. 